\title{
A GMC Oxidoreductase GmcA Is Required for Symbiotic Nitrogen Fixation in Rhizobium leguminosarum bv. viciae
}

\author{
Qian Zou, Sha Luo, Hetao Wu, Donglan He, Xiaohua Li and Guojun Cheng* \\ Hubei Provincial Engineering and Technology Research Center for Resources and Utilization of Microbiology, College of Life \\ Sciences, South-Central University for Nationalities, Wuhan, China
}

\section{OPEN ACCESS}

Edited by: Nikolay Vassilev,

University of Granada, Spain

Reviewed by:

Jose María Vinardell,

University of Seville, Spain

Clarisse Brigido,

University of Évora, Portugal

*Correspondence:

Guojun Cheng

chengguojun@mail.scuec.edu.cn

Specialty section:

This article was submitted to

Plant Microbe Interactions,

a section of the journal

Frontiers in Microbiology

Received: 18 November 2019

Accepted: 26 February 2020

Published: 24 March 2020

Citation:

Zou Q, Luo S, Wu H, He D, LiX

and Cheng G (2020) A GMC

Oxidoreductase GmcA Is Required

for Symbiotic Nitrogen Fixation

in Rhizobium leguminosarum bv. viciae. Front. Microbiol. 11:394. doi: 10.3389/fmicb.2020.00394
GmcA is a FAD-containing enzyme belonging to the GMC (glucose-methanol-choline oxidase) family of oxidoreductases. A mutation in the Rhizobium leguminosarum gmcA gene was generated by homologous recombination. The mutation in gmcA did not affect the growth of $R$. leguminosarum, but it displayed decreased antioxidative capacity at $\mathrm{H}_{2} \mathrm{O}_{2}$ conditions higher than $5 \mathrm{mM}$. The gmcA mutant strain displayed no difference of glutathione reductase activity, but significantly lower level of the glutathione peroxidase activity than the wild type. Although the gmcA mutant was able to induce the formation of nodules, the symbiotic ability was severely impaired, which led to an abnormal nodulation phenotype coupled to a $30 \%$ reduction in the nitrogen fixation capacity. The observation on ultrastructure of 4-week pea nodules showed that the mutant bacteroids tended to start senescence earlier and accumulate poly- $\beta$-hydroxybutyrate (PHB) granules. In addition, the gmcA mutant was severely impaired in rhizosphere colonization. Real-time quantitative PCR showed that the gmcA gene expression was significantly up-regulated in all the detected stages of nodule development, and statistically significant decreases in the expression of the redoxin genes katG, katE, and ohrB were found in gmcA mutant bacteroids. LC-MS/MS analysis quantitative proteomics techniques were employed to compare differential gmcA mutant root bacteroids in response to the wild type infection. Sixty differentially expressed proteins were identified including 33 up-regulated and 27 down-regulated proteins. By sorting the identified proteins according to metabolic function, 15 proteins were transporter protein, 12 proteins were related to stress response and virulence, and 9 proteins were related to transcription factor activity. Moreover, nine proteins related to amino acid metabolism were over-expressed.

Keywords: Rhizobium leguminosarum, the glucose-methanol-choline oxidoreductase GmcA, symbiotic nitrogen fixation, antioxidant and symbiotic gene expression, quantitative proteomics

\section{INTRODUCTION}

Rhizobium leguminosarum bv. viciae is an aerobic, Gram-negative, nitrogen-fixing bacterium that can live under the conditions of microaerobe, aerobe and form symbiotic relationships with Pisum sativum (pea) and Vicia cracca (vetch) under the condition of nitrogen limitation (Karunakaran et al., 2009). Organisms of this genus play a critical role in soil fertility, inducing the formation 
of symbiotic nodules on the roots of leguminous plants, where bacteroids reduce atmospheric nitrogen to ammonia available for plant uptake (Bhat et al., 2015). The symbiosis between rhizobia and legumes can be characterized by a mutual exchange of signal molecules between the two partners (Janczarek et al., 2015; López-Baena et al., 2016). After attachment of the bacteria to the plant root, the plant supports bacterial infection via hostderived infection threads (Haney and Long, 2010). Successful nodulation requires the activation of cell division in the cortex to form the nodule primordium (Blanco et al., 2009). In nodules, the nitrogenase enzyme, which is extremely sensitive to oxygen, has a low turnover number and a large requirement of chemical energy in the form of ATP and reducing potential (Clarke et al., 2011; Okazaki et al., 2015). In addition to reducing $\mathrm{N}_{2}$ and protons, nitrogenase can also reduce several small, non-physiological substrates, including a wide array of carboncontaining compounds (Seefeldt et al., 2013). It was found that uptake hydrogenases allow rhizobia to recycle the hydrogen generated in the nitrogen fixation process within the legume nodule (Baginsky et al., 2002).

Oxidoreductases catalyze a large variety of specific reduction, oxidation, and oxyfunctionalization reactions, which are important in redox processes, transferring electrons from a reductant to an oxidant (Hollmann and Schmid, 2004; Jeelani et al., 2010). Oxidoreductases included laccases, GMC (glucose-methanol-choline) oxidoreductases, copper radical oxidases and catalases (Beckett et al., 2015). The family of GMC flavoprotein oxidoreductases, which includes glucose/alcohol oxidase and glucose/choline dehydrogenase from prokaryotic and eukaryotic organisms, was first outlined by Cavener (1992). Members of the GMC oxidoreductase family share a common structural backbone of an adenine-dinucleotidephosphate-binding $\beta \alpha \beta$-fold close to their amino terminus (Iida et al., 2007). The group of GMC flavoprotein oxidoreductases encompasses glucose oxidase from the mold Aspergillus niger, the glucose dehydrogenase from Thermoplasma acidophilum and Drosophila melanogaster, methanol oxidase from yeast Hansenula polymorpha, and choline dehydrogenase from Escherichia coli (Ahmad et al., 2010; Liu et al., 2013). In the leaf beetle subtribe Chrysomelina sensu stricto, GMC oxidoreductases enabled chemical defenses and were important for adaptive processes in plant-insect interactions (Rahfeld et al., 2014). In E. coli, choline dehydrogenase catalyzes the flavin-dependent, two-step oxidation of choline to glycine betaine, which acts as an osmoprotectant compatible solute that accumulates when the cells are exposed to drastic environmental changes in osmolarity (Yilmaz and Bülow, 2010). However, little is known about the functional diversity of the rhizobium GMC family.

Rhizobium leguminosarum bv. viciae, which has been widely used as a model to study nodule biochemistry, is able to nodulate and fix nitrogen in symbiosis with several legumes (Karunakaran et al., 2009). Here, we investigated the roles of a GMC oxidoreductase GmcA in free-living bacteria and during nitrogen-fixing symbiosis on pea by analyzing the phenotypes of a mutant strain. Proteome analysis provides clues to explain the differences between the $g m c A$ mutant and wild-type nodules.

\section{MATERIALS AND METHODS}

\section{Bacterial Growth and Media}

The strains, plasmids and primers used in this study are listed in Table 1. Rhizobium strains were grown at $28^{\circ} \mathrm{C}$ in either Tryptone Yeast extract (TY) (Beringer and Hopwood, 1976) or Acid Minimal Salts medium (AMS) (Poole et al., 1994) with Dglucose $(10 \mathrm{mM})$ as a carbon source and $\mathrm{NH}_{4} \mathrm{Cl}(10 \mathrm{mM})$ as a $\mathrm{N}$ source (referred to as AMS Glc/ $\mathrm{NH}_{4}{ }^{+}$). For growth and qRT-PCR experiments, cells were grown in AMS Glc/ $\mathrm{NH}_{4}{ }^{+}$. Antibiotics were used at the following concentrations $(\mu \mathrm{g} / \mathrm{mL})$ : ampicillin (Amp), 50; gentamicin (Gm), 20; kanamycin (Km), 20; neomycin (Neo), 80; spectinomycin (Spe), 100; streptomycin (Str), 500; tetracycline (Tc), 5. Strains were grown at $28^{\circ} \mathrm{C}$ with shaking $(200 \mathrm{rpm})$ for liquid media. To monitor culture growth, optical density at $600 \mathrm{~nm}\left(\mathrm{OD}_{600}\right)$ was measured on three independent cultures.

\section{Construction and Complementation of the gmcA Gene Mutant of R. leguminosarum 3841}

Primers gmcAF and gmcAR were used to PCR amplify an internal region of the gmcA gene from $R$. leguminosarum bv. viciae 3841 genomic DNA (Johnston and Beringer, 1975). The 650-bp gmcA PCR product was cloned into the Pst I and XbaI sites of $\mathrm{pK} 19 \mathrm{mob}$, resulting in plasmid pKgmcA. The plasmid pKgmcA was conjugated with $R$. leguminosarum bv. viciae 3841 using pRK2013 as a helper plasmid, as previously described (Figurski and Helinski, 1979; Karunakaran et al., 2010). Insertions into the $g m c A$ gene of strain RL3841 were selected by neomycin resistant AMS medium with $30 \mathrm{mM}$ pyruvate as a sole carbon source and confirmed by PCR using MgmcA and a pK19mob-specific primer (either pK19A or pK19B) (Karunakaran et al., 2010).

To complement the gmcA mutant, primers cgmcAF and cgmcAR were used to amplify the complete $g m c A$ gene from strain RL3841. The PCR product was digested with $K p n \mathrm{I}$ and $\mathrm{XbaI}$ and cloned into pBBR1MCS-5, resulting in plasmid pBBRgmcA. Plasmid pBBRgmcA was conjugated into the mutant strain RLgmcA using pRK2013 as a helper plasmid to provide the transfer genes, as previously described (Karunakaran et al., 2010).

\section{Hydrogen Peroxide Resistance Activity}

Logarithmic phase cultures of mutant strain RLgmcA and wild-type RL3841 were collected and washed twice in sterile phosphate-buffered saline (PBS) $(1 \times ; 136 \mathrm{mM} \mathrm{NaCl}, 2.6 \mathrm{mM}$ $\mathrm{KCl}, 8.0 \mathrm{mM} \mathrm{Na}_{2} \mathrm{HPO}_{4}$, and $1.5 \mathrm{mM} \mathrm{KH}_{2} \mathrm{PO}_{4}$ ). Cells with an optical density $\left(\mathrm{OD}_{600}\right) 1$ were treated with $\mathrm{H}_{2} \mathrm{O}_{2}$ at different concentrations $(0,1,5$, and $10 \mathrm{mmol} / \mathrm{L})$ for $1 \mathrm{~h}$. Strains were thoroughly washed with distilled water to remove any remaining oxidant, and the diluted TY plate method was used to evaluate the bacterial survival rate. The experiment consisted of three independent experiments, each of which had three repeats, and statistical differences were analyzed with one-way ANOVA $(P<0.05)$. 
TABLE 1 | Strains, plasmids, and primers.

\begin{tabular}{|c|c|c|}
\hline Strains & Description & \\
\hline RL3841 & Rhizobium leguminosarum bv. viciae, $\mathrm{Str}^{\mathrm{r}}$ & \\
\hline RLgmcA & Rl3841 gmcA:pk19mob, $\operatorname{Str}^{r} \mathrm{Neo}^{r}$ & \\
\hline RLgmcA (pBBRgmcA) & RLgmcA carrying gmcA gene, $\mathrm{Str}^{r} \mathrm{Neo}^{r} \mathrm{Gm}^{r}$ & \\
\hline Plasmids & Description & \\
\hline pK19mob & pK19mob pUC19 derivative lacZ mob; Km & \\
\hline pRK2013 & Helper plasmid for mobilizing plasmids; $\mathrm{Km}^{\mathrm{r}}$ & \\
\hline pKgmcA & gmcAF/gmcAR PCR product in pK19mob, $\mathrm{Km}^{\mathrm{r}}$ & \\
\hline pBBRgmcA & cgmcAF/cgmcAR PCR product in pBBR1MCS-5, $\mathrm{Gm}^{r}$ & \\
\hline Primer & Description & Sequence $^{1}$ \\
\hline gmcAF & Sense primer for pRL100444 (gmcA) mutation & TाAGATCTGGCGGGTTCCTITGCGGTAA \\
\hline gmcAR & Antisense prime for pRL100444 (gmcA) mutation & TाCTGCAGTCAGCTCACCGGTCGCCTा \\
\hline MgmcA & Mapping PCR primer for gmcA gene & CGCCCGACGGATTGTAGAAT \\
\hline pK19A & pK19mob mapping primer & ATCAGATCTTGATCCCCTGC \\
\hline pK19B & pK19mob mapping primer & GCACGAGGGAGCTTCCAGGG \\
\hline gyrB1-F & Sense primer for qRT-PCR of GyrB1 & GGCATCACCAAAAGGGAAAA \\
\hline gyrB1-R & Antisense primer for qRT-PCR of GyrB1 & GCGAGGAGAATTTCGGATCA \\
\hline cgmcAF & Sense primer for gmcA complementation & TITGGTACCAGCTCACTGTCGATCTCTCC \\
\hline cgmcAR & Antisense prime for gmcA complementation & ПIICTAGACCTTATCCGGTTGAGCTGG \\
\hline QgmcA -for & Sense primer for qRT-PCR of $g m c A$ & CGCCGCCTCGCTCGGCAAGA \\
\hline QgmcA-rev & Antisense primer for qRT-PCR of gmcA & ATGCTCATGGAACTGCGAAG \\
\hline gyrB1-F & gyrB1 primers for qRT-PCR & GGCATCACCAAAAGGGAAAA \\
\hline gyrB1-R & & GCGAGGAGAATTCGGATCA \\
\hline QkatG-F & katG primers for qRT-PCR & GCAACTATTACGTCGGTCTG \\
\hline QkatG-R & & TCTCATCGATGACATITTCC \\
\hline QkatE-F & katE primers for qRT-PCR & CTCTCATCGATGACTTCCAT \\
\hline QkatE-R & & GGGACTCATATGTITCGAAG \\
\hline QorhB_F & Sense primer for qRT-PCR of orhB & CGGGCAGGCTGACATTGAGG \\
\hline QorhB_R & Antisense primer for qRT-PCR of orhB & GCTGCTCAGAGAAAGATCAC \\
\hline QhmuS-F & hmuS primers for qRT-PCR & AAGACCAGTCGCAGGAATTT \\
\hline QhmuS-R & & GAAGAACTCATGCGTATCGG \\
\hline QnifD_F & Sense primer for qRT-PCR of nifD & GCAACTATTACGTCGGTCTG \\
\hline QnifD_R & Antisense primer for qRT-PCR of nifD & TCTCATCGATGACATITTCC \\
\hline QfdxB_F & Sense primer for qRT-PCR of $f d x B$ & ATGGCGAAGACGACTITAAT \\
\hline QfdxB_R & Antisense primer for qRT-PCR of $f d x B$ & ATGAGTCTGGCAGTTCTTGG \\
\hline
\end{tabular}

${ }^{1}$ Restriction sites in primer sequences are underlined.

\section{Enzyme Activity Experiments}

For analysis of glutathione reductase and glutathione peroxidase activities, logarithmic phase cultures of mutant strain RLgmcA and wild-type RL3841 with an optical density $\left(\mathrm{OD}_{600}\right) 1$ were collected, and treated with $5 \mathrm{mM} \mathrm{H} \mathrm{H}_{2}$ for $1 \mathrm{~h} . \mathrm{H}_{2} \mathrm{O}_{2}$-treated PBS cells were collected by centrifugation at 5,000 rpm for $5 \mathrm{~min}$ at $4^{\circ} \mathrm{C}$. The cells were held in an ice-water bath and sonicated for $15 \mathrm{~min}$. The sonicate was centrifuged at $12,000 \mathrm{rpm}$ for $10 \mathrm{~min}$ at $4^{\circ} \mathrm{C}$. Glutathione reductase and glutathione peroxidase activities were determined using a peroxidase assay kit (Beyotime, China). The experiment consisted of three independent experiments, each of which had three repeats, and statistical differences were analyzed with one-way ANOVA $(P<0.05)$.

\section{Plant Growth and Microscope Study of Nodules}

Pea seeds were surface sterilized in 95\% ethanol for $30 \mathrm{~s}$ and then immersed in a solution of $2 \%$ sodium hypochlorite for 10 min. R. leguminosarum bv. viciae strains were inoculated with $10^{7} \mathrm{CFU}$ per seed at the time of sowing. Plants were incubated in a controlled-environment chamber with an 18$\mathrm{h}$ photoperiod (day/night temperature, 22 and $20^{\circ} \mathrm{C}$ ). For dry weight determination, plants were grown in a 2-L beaker filled with sterile vermiculite, watered with nitrogen-free nutrient solution and harvested at 7 weeks (Cheng et al., 2017). The shoot was removed from the root and dried at $70^{\circ} \mathrm{C}$ in a dry-heat incubator for 3 days before being weighed. Acetylene reduction was determined at flowering (4 weeks) in peas, as previously described (Allaway et al., 2000). The experiment consisted of two independent experiments, each of which had five repeats, and statistical differences were analyzed with one-way ANOVA $(P<0.05)$.

Nodules at 4 weeks post infection were fixed in 2.5\% glutaraldehyde and postfixed in $1.5 \%$ osmium tetroxide. Root nodules were sectioned and were then stained with toluidine blue. Ultra-thin sections stained with uranyl acetate and lead citrate were observed using a Hitachi H-7100 transmission electron microscope (Yan et al., 2004). For light microscopy, thick sections were cut on a microtome and stained. 


\section{Rhizosphere Colonization}

Rhizosphere colonization assays were performed as previously described (Cheng et al., 2017). Pea seedlings were grown for 7 days, as described above, for acetylene reduction, and inoculated with RLgmcA and RL3841 in the cfu ratios 1000:0, 0:1000, 1000:1000, and 10000:1000. After 7 days (14 days after sowing), shoots were cut-off and $20 \mathrm{~mL}$ of sterile phosphatebuffered saline (PBS) was added to the roots and vortexed for $15 \mathrm{~min}$ at speed 10 (Karunakaran et al., 2006). After vortexing, the samples were serially diluted and plate counted on TY medium plates containing either streptomycin (for wild-type RL3841 and mutant RLgmcA together) or streptomycin and neomycin (for RLgmcA), giving the total number of viable rhizosphere- and root-associated bacteria (Barr et al., 2008). Each treatment consisted of 10 replications, and statistical differences were analyzed with one-way ANOVA $(P<0.05)$.

\section{RNA Isolation and Quantitative Reverse Transcription-PCR (RT-PCR)}

Quantitative Real-Time RT-PCR was used to determine differences in the expression of genes. Cell samples were collected from free-living $R$. leguminosarum cultivated in AMS liquid medium, or free-living cells treated with $5 \mathrm{mM} \mathrm{H}_{2} \mathrm{O}_{2}$ for $1 \mathrm{~h}$ or root nodules, which were harvested from pea that had been inoculated with $R$. leguminosarum strains at 2, 4, and 6 weeks. The nodules of plants were harvested and grinded into a regular fine powder with liquid nitrogen. Total RNA of each sample was extracted using TRIzol Reagent (Invitrogen) and quantified by NanoDrop (Thermo Fisher Scientific) (Smith et al., 1985). cDNA was prepared using SuperScript ${ }^{\mathrm{TM}}$ II reverse transcriptase and random hexamers. Quantitative real-time PCR was performed using the SYBR Premix ExTaq (Takara, Dalian, China) on the BIO-RAD CFX96 Real-Time PCR Detection System. Primers for katG, katE, hmuS, ohrB, rhtA, and nifD are detailed in Table 1. Gyrb1 was used as a reference housekeeping gene and the obtained data were analyzed as previously described (Prell et al., 2009). Statistical analysis of data sets was performed using REST (Pfaffl et al., 2002).

\section{Protein Extraction and LC-MS/MS Analysis}

The 4-week-nodule samples were grinded into cell powder in liquid nitrogen. The cell powder was transferred to a $5-\mathrm{mL}$ centrifuge tube. Four volumes of lysis buffer ( $8 \mathrm{M}$ urea, $1 \%$ protease inhibitor cocktail) was then added to the cell powder, and the slurry was sonicated three times on ice using a high intensity ultrasonic processor. Cellular debris was removed by centrifugation at $12,000 \mathrm{~g}$ for $10 \mathrm{~min}$ at $4^{\circ} \mathrm{C}$, the supernatant was collected, and the protein content was determined using BCA protein assay kit (Pierce, Rockland, IL, United States). The resulting proteins were reduced by $5 \mathrm{mM}$ dithiothreitol at $56^{\circ} \mathrm{C}$ for $30 \mathrm{~min}$, and then alkylated in $11 \mathrm{mM}$ iodoacetamide for $15 \mathrm{~min}$ at room temperature in the dark. Each protein sample was then diluted by $100 \mathrm{mM}$ tetraethyl ammonium bromide (TEAB) to obtain a urea concentration of less than 2 and 1:100 trypsinto-protein mass ratio for a second digestion of $4 \mathrm{~h}$. Following trypsin digestion, the peptides then were desalted by Strata X C18 SPE column and vacuum-dried. The peptides were reconstituted in $0.5 \mathrm{M} \mathrm{TEAB}$ and processed according to the manufacturer's instructions of the tandem mass tag (TMT) kit (Thermo Fisher Scientific, Bremen, United States). Concisely, one unit of TMT reagent was dissolved and reconstituted in acetonitrile. The peptide mixtures were then incubated at room temperature for $2 \mathrm{~h}$ and pooled, desalted and dried by vacuum centrifugation.

The tryptic peptides were dissolved in solvent A $0.1 \%$ formic acid in aqueous solution) and loaded directly onto a reversed phase analytical column $(75 \mu \mathrm{m}$ i.d. $\times 15 \mathrm{~cm}$ length). The loaded material was eluted from this column in a linear gradient of 6$22 \%$ solvent B ( $0.1 \%$ formic acid in $98 \%$ acetonitrile) over $26 \mathrm{~min}$, $23-35 \%$ in $8 \mathrm{~min}$, climbing to $80 \%$ in $3 \mathrm{~min}$ and holding at $80 \%$ for 3 min with a flow rate of $400 \mathrm{~nL} / \mathrm{min}$. The MS proteomics data were deposited to NSI source, followed by tandem mass spectrometry (MS/MS) by using a Q Exactive ${ }^{\mathrm{TM}}$ Plus (Thermo) coupled online to the ultra-performance liquid chromatography (UPLC). The electrospray voltage was set to $2.0 \mathrm{kV}$. For the full scan mode, the $\mathrm{m} / \mathrm{z}$ scan range was from 350 to 1,800 . The intact peptides were detected in the Orbitrap at a resolution of 70,000. Peptides were selected to run MS/MS analysis using NCE setting as 28 and the fragments were measured using a resolution of 17,500 in the Orbitrap. The MS analysis alternated between MS and data-dependent tandem MS scans with $15.0 \mathrm{~s}$ dynamic exclusion. Automatic gain control (AGC) was set to accumulate $5 \times 10^{4}$ ions with the Fixed first mass of $100 \mathrm{~m} / \mathrm{z}$. Experiments were conducted in triplicate.

\section{Data Analysis}

The resulting MS/MS data were processed and prepared for a database search using the MaxQuant version 1.5.2.8 (Cox and Mann, 2008). The resulting tandem mass spectra were searched against the $R$. leguminosarum genome database concatenated with a reverse decoy database (Young et al., 2006). Trypsin/P was specified as the cleavage enzyme allowing up to four missing cleavages. The precursor mass tolerance was set to $20 \mathrm{ppm}$ for the first search and $5 \mathrm{ppm}$ for the main search, and the tolerance of the ions was set to $0.02 \mathrm{Da}$ for fragment ion matches. Carbamidomethylation of cysteines was considered as a fixed modification, and oxidation of methionine was specified as variable modifications. A false discovery rate (FDR) of $1 \%$ was specified, and the minimal peptide score for modified peptides was set to 40 . Protein expression was analyzed statistically using Student's $t$-tests $(p<0.05)$. Up-regulated and down-regulated proteins were defined as having fold changes $(\mathrm{FC})>1.2$ and $<0.83$, respectively.

\section{RESULTS}

\section{Bioinformatic Analysis of the R. leguminosarum gmcA Gene}

Rhizobium leguminosarum gmcA gene ( $p R L 100444)$ is predicted to encode a 550-amino acid polypeptide with an expected molecular mass of $60.5 \mathrm{kDa}$ and a $\mathrm{pI}$ value of 8.19 (Young et al., 2006). The amino acid sequence of GmcA contained 
TABLE 2 | Tolerance of $R$. leguminosarum stains to different concentrations of $\mathrm{H}_{2} \mathrm{O}_{2}$.

\begin{tabular}{|c|c|c|c|c|c|}
\hline \multirow[t]{2}{*}{ Strain } & \multicolumn{5}{|c|}{$\mathrm{H}_{2} \mathrm{O}_{2}(\mathrm{mM})$} \\
\hline & 0 & 0.5 & 1.0 & 5.0 & 10.0 \\
\hline RL3841 & $(6.72 \pm 0.71) \times 10^{8 a}$ & $(4.27 \pm 0.27) \times 10^{8 a}$ & $(3.85 \pm 0.18) \times 10^{8 a}$ & $(2.73 \pm 0.14) \times 10^{7 a}$ & $(1.01 \pm 0.21) \times 10^{7 a}$ \\
\hline RLgmcA & $(7.03 \pm 1.00) \times 10^{8 a}$ & $(3.80 \pm 0.17) \times 10^{8 a}$ & $(3.21 \pm 0.29) \times 10^{8 a}$ & $(1.59 \pm 0.19) \times 10^{7 b}$ & $(4.07 \pm 0.90) \times 10^{6 b}$ \\
\hline
\end{tabular}

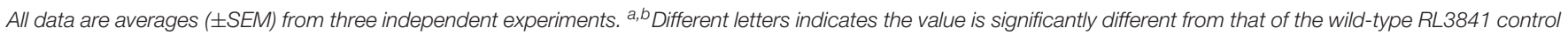
(one-way ANOVA, $P<0.05$ ).

a consensus motif of a $\mathrm{FAD} / \mathrm{NAD}(\mathrm{P})$-binding domain in its $\mathrm{N}$-terminal part and two GMC oxidoreductase signature patterns (Supplementary Figure S1), suggesting that GmcA should be included into the glucose-methanol-choline (GMC) flavindependent oxidoreductase family.

\section{Antioxidation Analysis of a R. leguminosarum gmcA Mutant}

To confirm the function of the gmcA gene in growth performance, antioxidation and symbiotic nitrogen fixation ability, a mutant RLgmcA strain of this gene was constructed by single crossover homologous recombination. In liquid AMS minimal medium with glucose as a carbon source and $\mathrm{NH}_{4} \mathrm{Cl}$ as a nitrogen source, there is no significant difference in growth between the mutant RLgmcA and wild-type RL3841 (data not shown).

The importance of GmcA for protection against oxidative stress was investigated by carrying out survival assays of the mutant RLgmcA in the presence of oxide hydrogen peroxide $\left(\mathrm{H}_{2} \mathrm{O}_{2}\right)$. The survival rates of RLgmcA were not significantly affected by $\mathrm{H}_{2} \mathrm{O}_{2}$ treatments at low concentrations of 0.5 and $1 \mathrm{mmol} / \mathrm{L}$ compared with the wild-type RL3841 strain, whereas the antioxidative capacity of mutant RLgmcA was significantly decreased by these treatments with $\mathrm{H}_{2} \mathrm{O}_{2}$ at higher concentrations of 5 and $10 \mathrm{mmol} / \mathrm{L}$ (Table 2). The role of R. leguminosarum $\mathrm{GmcA}$ in controlling protein glutathionylation status was investigated by quantifying glutathione reductase and glutathione peroxidase activities in $5 \mathrm{mM} \mathrm{H}_{2} \mathrm{O}_{2}$-induced oxidative stress conditions. The results showed that the glutathione reductase activity of mutant RLgmcA was not different from that of wild-type strain RL3841, but its glutathione peroxidase activity was significantly lower (Table 3). Thus, GmcA may play important roles in oxidative stress resistance and cellular detoxification in $R$. leguminosarum.

\section{Pea Rhizosphere Colonization by \\ R. leguminosarum Strains}

Competition between the gmcA mutant RLgmcA and the wild type RL3841 for growth in the pea rhizosphere was measured by inoculating a low number of bacteria into the pea rhizosphere $\left(10^{3}\right.$ to $10^{4}$ bacteria per seedling) and determining total bacteria after 7 days. When the mutant RLgmcA and the wild type RL3841 were inoculated alone into short-term colonization of sterile pea rhizosphere, the percentage of bacteria recovered after 7 days was significantly lower for the mutant than for the wt strain (Figure 1). When inoculated in equal ratios, RLgmcA accounted
TABLE 3 | Oxidase activity of $R$. leguminosarum gmcA mutant.

\begin{tabular}{lcc}
\hline Strains R. leguminosarum & $\begin{array}{c}\text { Glutathione } \\
\text { reductase } \\
\text { (U/mg } \\
\text { protein) }\end{array}$ & $\begin{array}{c}\text { Glutathione } \\
\text { peroxidase } \\
\text { (U/mg } \\
\text { protein) }\end{array}$ \\
\hline RL3841 & $0.399 \pm 0.041^{a}$ & $0.406 \pm 0.029^{a}$ \\
RLgmcA & $0.408 \pm 0.031^{a}$ & $0.018 \pm 0.006^{\mathrm{b}}$ \\
RLgmcA(pBBRgmcA) & $0.409 \pm 0.030^{\mathrm{a}}$ & $0.385 \pm 0.031^{\mathrm{a}}$
\end{tabular}

All data are averages ( \pm SEM) from three independent experiments. ${ }^{a, b}$ Different letters indicates the value is significantly different from that of the wild-type RL3841 control (one-way ANOVA, $P<0.05$ ).

for only $25 \%$ of bacteria recovered ( $t$-test; $P \leq 0.01$ ). Even when strain RLgmcA was inoculated at a 10 -fold excess over the wild type, it still accounted for only $41 \%$ of bacteria recovered (Figure 1). The decreased ability of the $g m c A$ mutant to grow in a sterile rhizosphere of peas shows that GmcA is essential for colonization of the pea rhizosphere by R. leguminosarum.

\section{The Symbiotic Phenotype of R. leguminosarum Strains}

To observe the nodulation status and measure nitrogenase activity of the $g m c A$ mutant strain, pea seedlings were inoculated with the mutant RLgmcA or wild-type RL3841. Four weeks later, the number, shape and structure, and acetylene reduction activity (ARA) values of the nodules were measured. No statistically significant difference was observed in the number of nodules per plant between plants inoculated strain RLgmcA and plants inoculated with wild-type RL3841 (Table 4 and Supplementary Figure S2). R. leguminosarum bv. viciae formed determinate nodules on pea, while the $g m c A$ mutant elicited more elongated, rather than spherical, nodules compared to the wild type and showed a $30.36 \%$ decrease in ARA and a $40 \%$ drop in the dry weight of plants compared to the wild type (Table 4). When recombinant plasmid pBBRgmcA was introduced into mutant RLgmcA, plants inoculated with the resulting strain $\mathrm{RLgmcA}(\mathrm{pBBRgmcA})$ formed normal nodules and showed no significant difference in nitrogen-fixing ability and the dry weight of plants compared to the RL3841-inoculated plants (Table 4).

Four-week-old nodules were further examined by both light and electron microscopy. The nodules induced both by wild type RL3841 and by mutant RLgmcA turned blue when stained with toluidine blue. These observations were corroborated by light microscopic analysis. Both the nodules were filled 


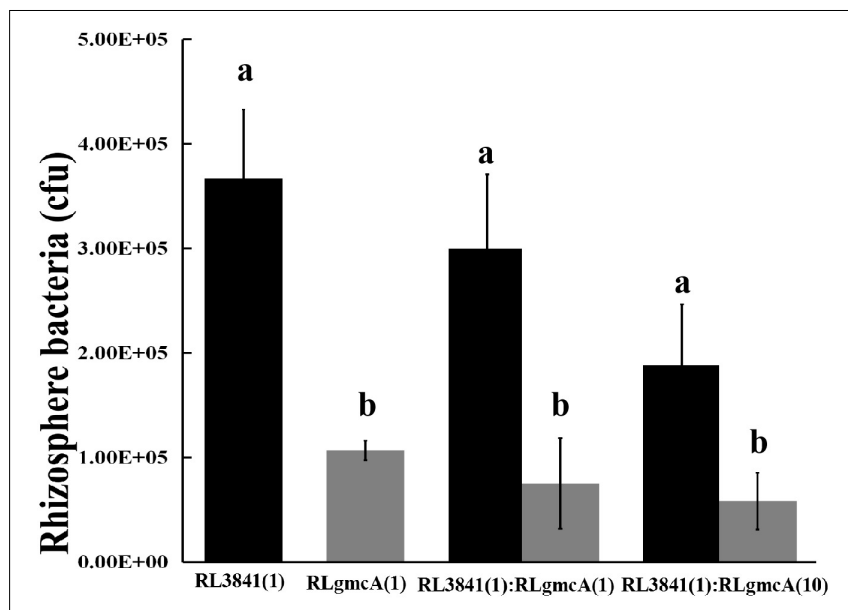

FIGURE 1 | Competition of the wild type (RL3841) (black bars) and the gmcA mutant (RLgmcA) (gray bars) in sterile rhizospheres. Inoculation ratios are given on the $x$-axis, with 1 corresponding to 1,000 CFU. Number of bacteria (per plant) recovered from 10 plants (mean \pm SEM) are shown. ${ }^{\text {a,b }}{ }^{\text {Different }}$ letters indicate the value is significantly different between mutant RLgmcA and wild-type RL3841 control (one-way ANOVA, $P<0.05$ ).

by Rhizobia-infected cells (Figures 2B,C). The ultrastructural structure of the infected cells was observed by transmission electron microscopy. In the mutant infected nodule cells, bacteroids underwent premature senescence. Bacteroids in pea plants inoculated by $R$. leguminosarum bv. viciae usually did not produce visible PHB granules, but in the mutant bacteroids, the poly-b-hydroxybutyrate (PHB) was also distinctly observed (Figure 2).

\section{Expression Level of the gmcA Gene in Nodules Induced by $R$. leguminosarum 3841}

The expression of $g m c A$ was significantly up-regulated in the early stage (14 days), maturation stage (28 days) and late stage (42 days) of nodule development and senescence in comparison to that in free-living cells (Figure 3). During symbiosis, gmcA gene has the highest expression level in nodules at 42 days after inoculation. Thus, these results showed that gmcA gene expression was induced during $R$. leguminosarum-pea symbiosis and suggest that this gene plays an important role in bacteroid persistence in old nodules.

\section{Analysis of the Relative Expression of Genes Involved in Redoxin Production and Nitrogen Fixation in the gmcA Mutant}

As shown in Figure 4A, under $5 \mathrm{mmol} / \mathrm{L} \mathrm{H}_{2} \mathrm{O}_{2}$-induced oxidative stress condition, a significant decrease in kat $G$, $f d x B$, and $h m u S$ gene expression was observed in the $g m c A$ mutant, suggesting that GmcA plays an important role in cellular redox balance. Since a large reduction in the nitrogenfixing capacity of nodules inoculated with mutant strain was observed, qRT-PCR was used to assess whether the $\mathrm{N}$-fixation system, e.g., nitrogenase genes, was affected in the transcription of ribosomal RNAs in the GmcA-deficient mutant. The expression of nifD and $f d x B$ was analyzed in pea root nodules using qRT-PCR (Figure 4B). Unexpectedly, the expression level of nifD and $\mathrm{fdxB}$ was found to be significantly increased in 4 -week-old nodules inoculated with gmcA mutant strain compared with control nodules. Thus, GmcA may function in redox balance and antioxidant defense system in the pea root nodules. hmuS gene expression was significantly down-regulated in $g m c A$ mutant, both under $\mathrm{H}_{2} \mathrm{O}_{2}$ induced oxidative stress condition and in 4-week-old nodule, suggesting $g m c A$ is involved in iron transport and regulation of iron homeostasis.

\section{Protein Differential Expression Analysis}

A quantitative proteomic approach using UPLC coupled with tandem mass spectrometry (LC/LC-MS/MS) was performed to compare differential gmcA mutant root bacteroids in response to wild type infection. Proteomics analysis identified peptides derived from a total of 2002 distinct protein groups in $g m c A$ mutant bacteroids and 2000 in wild-type bacteroids, with molecular weights ranging from 7 to $317 \mathrm{kDa}$. A total of 60 differentially expressed proteins $(P<0.05)$ were identified. Among these proteins (Table 5), 33 proteins were up-regulated in $g m c A$ mutant nodule bacteroids and 27 proteins were down-regulated. Cell surface protein (RL4381) was absent in the $g m c A$ mutant bacteroids, while invasion associated protein (RL1020) and lipoate-protein ligase B (RL2555) were not found in the wild-type bacteroids. Thirty-two differential protein-encoding genes were localized in plasmids pRL7, pRL8, pRL9, pRL10, pRL11, and pRL12. Cellular localization of the differentially expressed proteins showed that thirty-nine proteins localized to the cytoplasm, thirteen proteins localized to periplasmic

TABLE 4 | Symbiotic behavior of $R$. leguminosarum gmcA mutant.

\begin{tabular}{|c|c|c|c|}
\hline Strain & Nodules per plant & Acetylene reduction ( $\mu$ moles acetylene per plant per $\mathrm{h}$ ) & Dry weight per plant (g) \\
\hline RL3841 & $137.3 \pm 13.2^{\mathrm{a}}$ & $2.24 \pm 0.14^{a}$ & $1.86 \pm 0.20^{a}$ \\
\hline RLgmcA & $131.3 \pm 11.3^{a}$ & $1.56 \pm 0.05^{b}$ & $1.10 \pm 0.18^{b}$ \\
\hline RLgmcA(pBBRgmcA) & $135.5 \pm 11.3^{\mathrm{a}}$ & $2.12 \pm 0.16^{a}$ & $1.80 \pm 0.16^{a}$ \\
\hline WC & 0 & 0 & $0.35 \pm 0.09^{c}$ \\
\hline
\end{tabular}

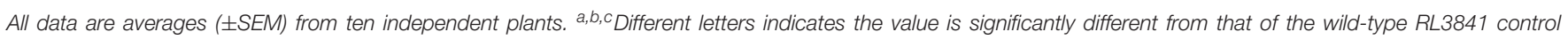
(one-way ANOVA, $P<0.05$ ). WC, water control without inoculation. 

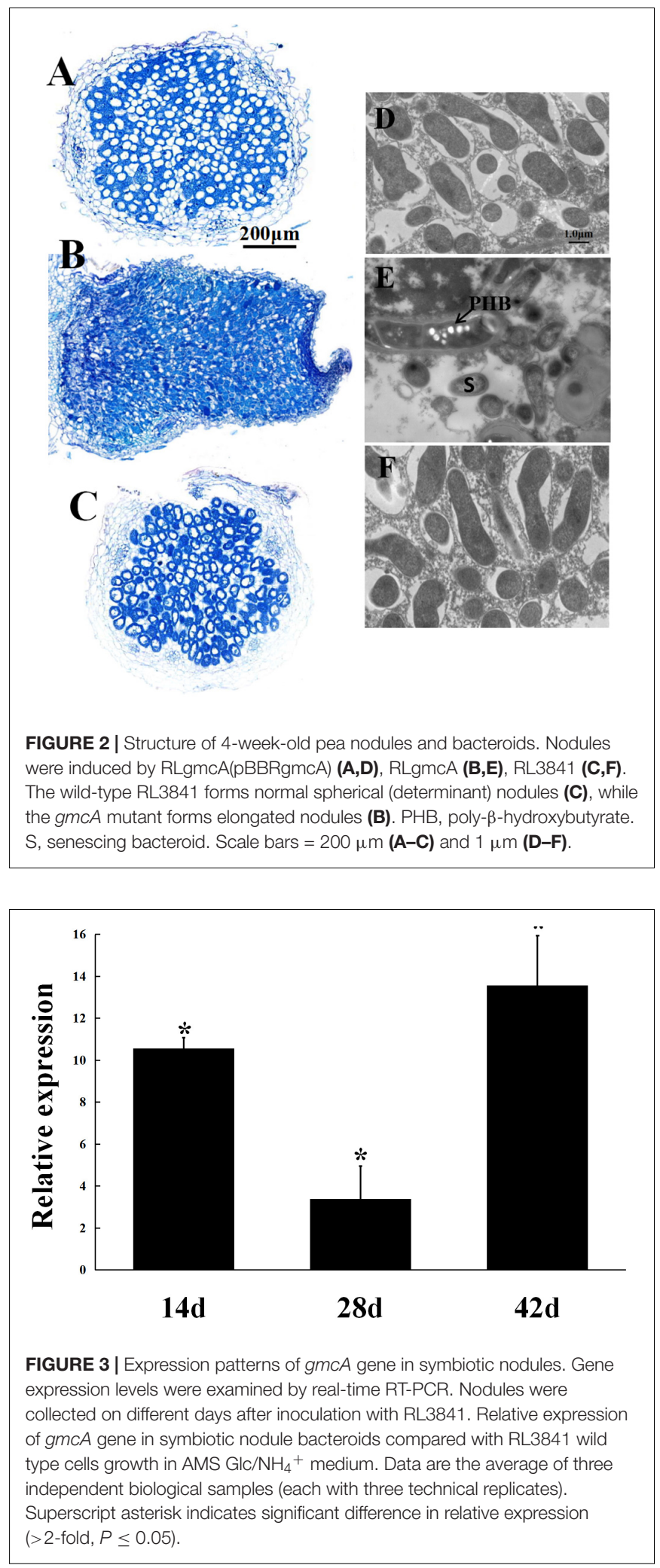

space, five proteins located in the outer membrane, two were extracellular proteins, and one protein existed in the inner membrane (Table 5).

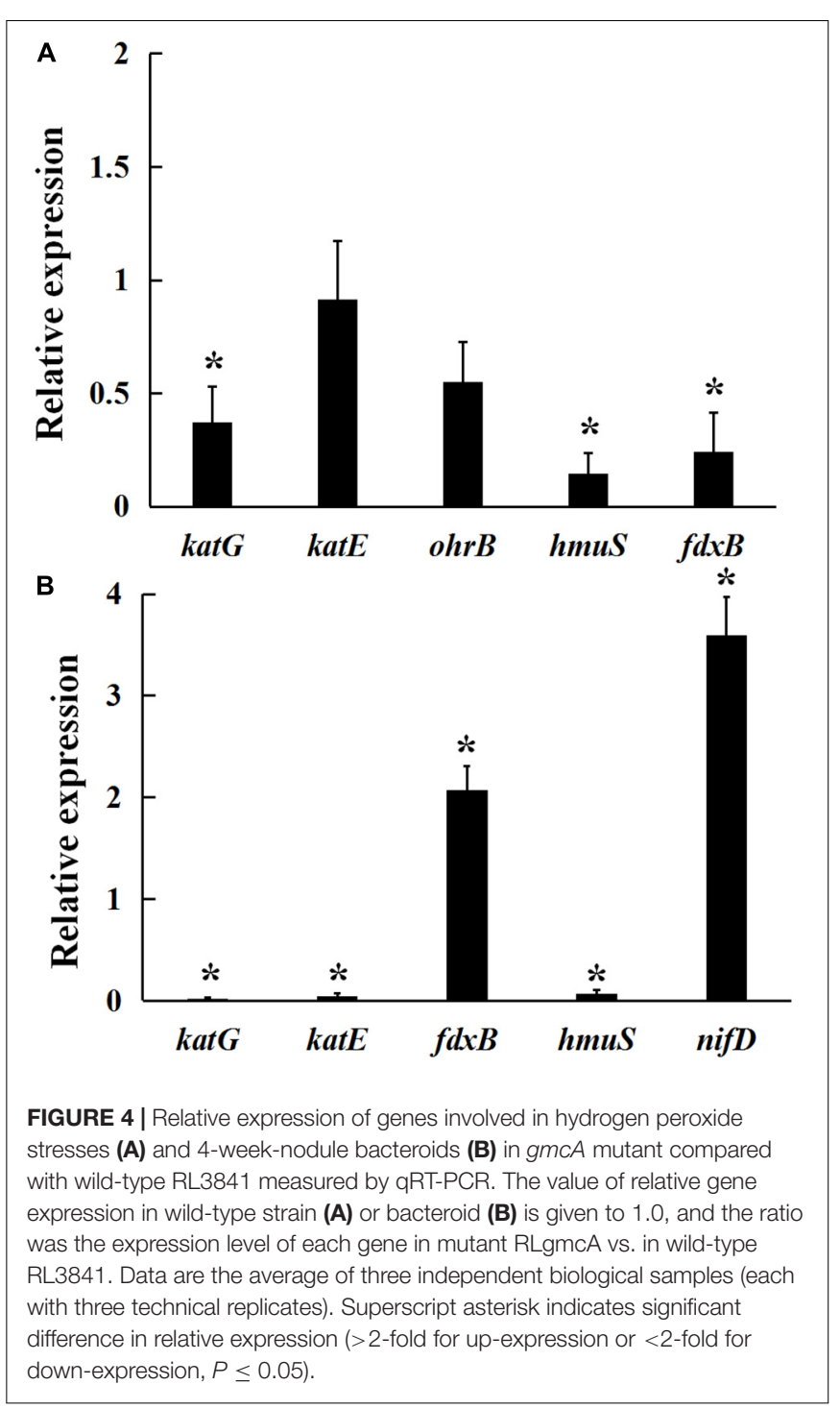

By sorting the identified proteins according to metabolic function, most of the differences in expression were found among transporter activity ( 15 proteins), followed by 12 proteins related to stress response and virulence, 9 proteins related to transcription factor activity, 7 proteins related to amino acid metabolism, 6 proteins related to carbohydrate metabolism, and 4 proteins related to nucleotide metabolism. This change in metabolism was mirrored by corresponding changes in proteins involved in the regulation of transcription, among which, a nifspecific transcriptional activator NifA and a nitrogen regulatory protein PtsN were highly expressed in the mutant bacteroids. The main groups of differentially expressed proteins identified were transport proteins, of which 6 were ABC-type nitrate/nitrite transporters. The result showed gmcA mutant was affected in transport, especially in nitrate transport. Further analysis of the differentially expressed proteins identified a subset involved in stress response and virulence. The number of affected oxidoreductases, cytochrome oxidase, dehydrogenase, hydrolase, dehydrogenase, surface, and invasion associated proteins also 
TABLE 5 | Differential expression proteins in 4-week nodule mutant bacteroids relative to wild-type bacteroids.

\begin{tabular}{|c|c|c|c|c|c|c|c|}
\hline Gene ID & Gene Name & Cellular localization & Protein description & MW [kDa] & pl & Ratio & $P$-value \\
\hline \multicolumn{8}{|c|}{ Stress response and virulence } \\
\hline RL3853 & & Cytoplasmic & FAD-dependent oxidoreductase & 47.38 & 5.71 & 6.15 & 0.0004 \\
\hline RL4381 & & Outermembrane & cell surface protein & 66.06 & 4.46 & 1.58 & NP1 \\
\hline pRL90097 & $p d x A 2$ & Cytoplasmic & 4-hydroxythreonine-4-phosphate dehydrogenase & 34.66 & 6.39 & 1.23 & 0.0332 \\
\hline pRL100245 & & Cytoplasmic & LLM class flavin-dependent oxidoreductase & 38.97 & 5.20 & 1.22 & 0.0082 \\
\hline pRL80022 & & Cytoplasmic & alpha/beta hydrolase & 35.12 & 6.03 & -0.40 & 0.0011 \\
\hline pRL80023 & cutM & Cytoplasmic & carbon monoxide dehydrogenase subunit M protein & 30.42 & 5.56 & -0.48 & 0.0012 \\
\hline pRL80041 & his $D$ & Cytoplasmic & Histidinol dehydrogenase & 47.16 & 5.39 & -0.60 & 0.0115 \\
\hline RL1020 & & Periplasmic & invasion associated protein & 22.08 & 5.45 & -0.85 & NP2 \\
\hline pRL120603 & gabD3 & Cytoplasmic & NAD-dependent succinate-semialdehyde dehydrogenase & 52.53 & 5.29 & -0.74 & 0.0344 \\
\hline pRL90027 & adhA & Cytoplasmic & alcohol dehydrogenase & 37.15 & 5.93 & -0.77 & 0.0008 \\
\hline pRL120056 & $m c p R$ & Cytoplasmic & methyl-accepting chemotaxis protein & 68.73 & 5.01 & -0.77 & 0.0426 \\
\hline pRL90018 & fixN2 & Innermembrane & Putative cytochrome oxidase transmembrane component FixN & 60.90 & 8.98 & -0.82 & 0.0074 \\
\hline \multicolumn{8}{|c|}{ Amino acid metabolism } \\
\hline pRL100242 & & Cytoplasmic & amino acid synthesis family protein & 21.17 & 6.29 & 1.45 & 0.0159 \\
\hline pRL110557 & $g \mid x B$ & Cytoplasmic & glutamine amidotransferase & 31.99 & 5.21 & 1.42 & 0.0190 \\
\hline RL0041 & hisE & Cytoplasmic & Phosphoribosyl-ATP pyrophosphatase & 11.51 & 5.19 & 1.30 & 0.0496 \\
\hline pRL100099 & & Cytoplasmic & Nif11 family protein & 14.45 & 8.86 & 1.23 & 0.0152 \\
\hline RL2075 & gatC & Cytoplasmic & Aspartyl/glutamyl-tRNA(Asn/Gln) amidotransferase subunit C & 10.19 & 4.73 & 1.22 & 0.0082 \\
\hline pRL100192 & & Outermembrane & glutamate N-acetyltransferase & 20.33 & 6.71 & 1.21 & 0.0024 \\
\hline pRL90221 & & Cytoplasmic & Putative glutamine amidotransferase protein & 28.31 & 5.18 & -0.72 & 0.0244 \\
\hline \multicolumn{8}{|c|}{ Carbohydrate metabolism } \\
\hline pRL110453 & & Cytoplasmic & Concanavalin A-like lectin/glucanase domain & 22.05 & 5.00 & 1.25 & 0.0237 \\
\hline RL0916 & dgoK & Cytoplasmic & 2-dehydro-3-deoxygalactonokinase & 31.49 & 5.69 & -0.73 & 0.0076 \\
\hline RL0874 & RL0874 & Cytoplasmic & aldo/keto reductase & 38.21 & 5.45 & -0.78 & 0.0000 \\
\hline pRL110598 & & Cytoplasmic & L-fuconate dehydratase & 47.20 & 5.17 & -0.82 & 0.0137 \\
\hline pRL120643 & grosp12 & Cytoplasmic & co-chaperone GroES & 11.37 & 5.48 & -0.83 & 0.0003 \\
\hline RL2555 & $\operatorname{lip} B$ & Cytoplasmic & lipoate-protein ligase B & 26.70 & 5.22 & -0.99 & NP2 \\
\hline \multicolumn{8}{|c|}{ Transporter activity } \\
\hline RL4326 & & Periplasmic & Putative transmembrane protein & 98.15 & 5.59 & 1.39 & 0.0122 \\
\hline RL3066 & & Periplasmic & Putative transmembrane protein & 17.22 & 8.09 & 1.35 & 0.0090 \\
\hline RL2491 & & Cytoplasmic & Conserved hypothetical exported protein & 9.75 & 5.38 & 1.28 & 0.0001 \\
\hline pRL100386 & & Periplasmic & WWA domain-containing protein & 74.90 & 4.84 & 1.24 & 0.0122 \\
\hline RL3065 & & Periplasmic & Conserved hypothetical exported protein & 14.77 & 5.88 & 1.23 & 0.0151 \\
\hline pRL70182 & & Periplasmic & Conserved hypothetical exported protein & 36.84 & 5.32 & 1.21 & 0.0265 \\
\hline pRL80026 & livJ & Periplasmic & $\mathrm{ABC}$ transporter substrate-binding protein & 45.36 & 5.81 & -0.33 & 0.0006 \\
\hline pRL80060 & & Periplasmic & ABC transporter substrate-binding protein & 29.75 & 5.35 & -0.53 & 0.0007 \\
\hline pRL80085 & & Cytoplasmic & Autoinducer $2 \mathrm{ABC}$ transporter substrate-binding protein & 35.70 & 6.02 & -0.60 & 0.0448 \\
\hline RL2775 & ropA1 & Outermembrane & Porin & 36.80 & 3.92 & -0.71 & 0.0111 \\
\hline RL4402 & & Cytoplasmic & ABC transporter substrate-binding protein & 35.94 & 4.96 & -0.72 & 0.0115 \\
\hline RL1499 & ropA2 & Outermembrane & Porin & 36.71 & 4.01 & -0.77 & 0.0001 \\
\hline pRL100415 & & Periplasmic & ABC transporter substrate-binding protein & 37.92 & 5.17 & -0.79 & 0.0492 \\
\hline pRL120671 & & Periplasmic & nitrate $\mathrm{ABC}$ transporter substrate-binding protein & 36.00 & 5.50 & -0.83 & 0.0123 \\
\hline pRL100325 & fhuA1 & Outermembrane & outer membrane siderophore receptor & 78.19 & 4.64 & -0.83 & 0.0203 \\
\hline \multicolumn{8}{|c|}{ Nucleotide metabolism } \\
\hline RL0952 & & Cytoplasmic & RNA-binding domain transcriptional regulator & 83.38 & 6.67 & 1.34 & 0.0278 \\
\hline RL2475 & holB & Cytoplasmic & Putative DNA polymerase III, delta subunit & 36.35 & 5.90 & 1.26 & 0.0409 \\
\hline RL1785 & rplX & Cytoplasmic & $50 S$ ribosomal protein L5 & 11.21 & 10.37 & 1.23 & 0.0038 \\
\hline RL2183 & & Cytoplasmic & nucleotidyltransferase & 33.59 & 8.80 & -0.82 & 0.017 \\
\hline \multicolumn{8}{|c|}{ Transcription factor activity } \\
\hline pRL100146 & & Periplasmic & transcriptional regulator & 23.94 & 9.57 & 1.33 & 0.0243 \\
\hline RL4412 & priA & Cytoplasmic & primosome assembly protein PriA & 80.82 & 6.32 & 1.30 & 0.0382 \\
\hline
\end{tabular}


TABLE 5 | Continued

\begin{tabular}{|c|c|c|c|c|c|c|c|}
\hline Gene ID & Gene Name & Cellular localization & Protein description & MW [kDa] & pl & Ratio & $P$-value \\
\hline RL3457 & & Extracellular & SH3-like domain, bacterial-type; uncharacterized protein & 21.84 & 4.62 & 1.25 & 0.0082 \\
\hline RL0425 & $p t s N$ & Cytoplasmic & PTS IA-like nitrogen regulatory protein PtsN & 16.65 & 5.70 & 1.23 & 0.0007 \\
\hline RL1379 & rosR & Cytoplasmic & MucR family transcriptional regulator & 15.62 & 6.96 & 1.22 & 0.0055 \\
\hline RL0133 & & Cytoplasmic & YbaB/EbfC family nucleoid-associated protein & 11.42 & 5.18 & 1.22 & 0.0007 \\
\hline pRL100196 & nifA & Cytoplasmic & nif-specific transcriptional activator & 56.46 & 9.05 & 1.21 & 0.0011 \\
\hline pRL80079 & & Cytoplasmic & sugar-binding transcriptional regulator & 35.34 & 5.71 & -0.38 & 0.0072 \\
\hline pRL80046 & & Cytoplasmic & TetR/AcrR family transcriptional regulator & 25.32 & 8.01 & -0.46 & 0.0112 \\
\hline \multicolumn{8}{|c|}{ Unknown function proteins } \\
\hline pRL100106 & & Periplasmic & Uncharacterized protein & 28.65 & 6.19 & 1.59 & 0.0363 \\
\hline RL1874 & & Cytoplasmic & Uncharacterized protein & 13.23 & 4.66 & 1.35 & 0.0185 \\
\hline RL3516 & & Extracellular & DUF2076 domain-containing protein & 27.48 & 4.26 & 1.24 & 0.0017 \\
\hline RL4728 & & Periplasmic & DUF1013 domain-containing protein & 26.14 & 5.91 & 1.23 & 0.0005 \\
\hline RL2820 & & Cytoplasmic & Uncharacterized protein & 7.40 & 9.46 & 1.23 & 0.0494 \\
\hline pRL80010 & & Cytoplasmic & Uncharacterized protein & 9.58 & 9.51 & -0.21 & 0.0189 \\
\hline pRL80005 & & Cytoplasmic & Uncharacterized protein & 59.58 & 5.52 & -0.47 & 0.0028 \\
\hline
\end{tabular}

Protein expression was analyzed statistically using Student's t-tests $(P<0.05)$. Np1, no protein in mutant; Np2, no protein detected in wild type.

suggests that GmcA function in antioxidant capacity in the root nodules and that the loss of these proteins could result in antioxidant defect. Finally, the loss of GmcA resulted in the differential expression of seven proteins with unknown function in the nodule bacteroids.

\section{DISCUSSION}

The family of GMC oxidoreductases includes glucose/alcohol oxidase and glucose/choline dehydrogenase. Members of this family catalyze a wide variety of redox reactions with respect to substrates and co-substrates (Sützl et al., 2018). An important issue is that $g m c A$ expression is elevated in nitrogen-fixing bacteroids of the pea root nodules, but the function of $\mathrm{GmcA}$ in root nodule bacteria nitrogen fixing system is poorly understood. In this study, we took advantage of a $g m c A$ mutant strain of $R$. leguminosarum to examine what role GmcA may play in symbiotic nitrogen fixation. Our data demonstrated that GmcA is required for the nodule senescence and cellular detoxification that is affected, regarding its nitrogen fixation capacity and oxidative stress response.

Mutation of R. leguminosarum gmcA did not affect the growth of free-living bacteria but led to decreased antioxidative capacity under the conditions of 5 and $10 \mathrm{mM}$ hydrogen peroxide $\mathrm{H}_{2} \mathrm{O}_{2}$. The direct link between $\mathrm{GmcA}$ and $\mathrm{H}_{2} \mathrm{O}_{2}$ detoxification has been less reported, while in most wood-rotting fungi, the members of GMC oxidoreductase superfamily play a central role in the degradation process because they generate extracellular $\mathrm{H}_{2} \mathrm{O}_{2}$, acting as the ultimate oxidizer (Ferreira et al., 2015). Our results suggested that cells with GmcA tolerate internally generated or exogenously applied $\mathrm{H}_{2} \mathrm{O}_{2}$. Cellular oxidoreductases catalyze redox processes by transferring electrons from a reductant to oxidant and are important for protection against oxidative stress (Bisogno et al., 2010). The ferredoxin-like protein (FdxB) and iron transport protein $\mathrm{HmuS}$ are ubiquitous electron transfer proteins participating in the iron-sulfur cluster biosynthesis and a wide variety of redox reactions (Chao et al., 2005; Gu et al., 2008). In Rhizobium, the peroxidases and the catalases KatG (catalase HPI), KatE (catalase), and OhrB (organic hydroperoxide resistance) were known to participate in the antioxidant defense mechanism against $\mathrm{H}_{2} \mathrm{O}_{2}$-induced stress (Vargas Mdel et al., 2003), and the two electron transfer proteins FdxB and HmuS are also involved in a wide variety of redox reactions (Chao et al., 2005; Gu et al., 2008). This cell cytotoxicity was relieved by inducing transcription of antioxidant genes (Jung and Kim, 2003). Expression levels of katG, $f d x B$, and $h m u S$ genes were significantly down-regulated in the $g m c A$ mutant under $\mathrm{H}_{2} \mathrm{O}_{2}$-induced oxidative stress. It has been reported that decreased ferredoxin-NADP $(\mathrm{H})$ oxidoreductase (FNR) results in a more oxidized glutathione pool, while increasing FNR content results in a more reduced glutathione pool (Goss et al., 2012). Glutathione reductase activity in mutant RLgmcA was not different from that wild-type strain, but the absence of GmcA was associated with a $96.5 \%$ decrease in cellular glutathione peroxidase activity. Cellular peroxide deficit damages cellular macromolecules by reactive oxygen species (ROS), and glutathione peroxidases are one of the important ROS scavengers in the cell (Islam et al., 2015). The decrease of glutathione peroxidase activity is related to an uncontrolled increase of ROS (Giergiel et al., 2012).

Pea plants inoculated with the gmcA mutant exhibited a large decrease in the nitrogen-fixing activity of root nodules (reduced by more than 30\%), although, the protein expression of NifA and PtsN was higher in the mutant bacteroids compared to that of wild type bacteroids. Two genes, nifD and $f d x B$, involved in metabolism related to nitrogen fixation and bacteroid maturation in pea root nodules (Capela et al., 2006) also had a higher level of expression in the mutant bacteroids. It has been reported that GMC oxidoreductases are involved in extracellular hydrogen peroxide and iron homeostasis (Rohr et al., 2013). Iron is required for symbiotic nitrogen fixation as a key component 
of multiple ferroproteins involved in this important biological process (Takanashi et al., 2013). hmuS was chosen based on previous studies, which showed that it was involved in iron transport (Chao et al., 2005). hmuS exhibited higher expression level in the mutant bacteroids, demonstrating the involvement of GMC in the regulation of iron homeostasis. Proteomic analysis of the mutant nodule bacteroids indicated that most of the differentially expressed proteins were involved in transporter activity, metabolism, and stress responses. These transporters may aid in regulation of ion and membrane potential homeostasis through their transport of nitrate, which is known to regulate the symbiosis (Vincill et al., 2005). These results indicated that GmcA is involved in a variety of metabolic processes, as has been described in A. niger and E. coli (Etxebeste et al., 2012; Liu et al., 2013).

The electron microscope investigation revealed that $g m c A$ mutant altered the ultrastructure of pea nodules. GmcA can likely play a role in nodule senescence, since senescent parameters such as increased activities of enzymes of amino acid metabolism, $\mathrm{PHB}$ production, and an increase in the number of disintegrated bacteroids occurred. In addition, glutathione peroxidase activity dramatically decreased, and amino acid metabolism reflecting arginase activity was increased. R. leguminosarum bv. viciae forms determinate nodules on pea and usually does not produce visible PHB granules during symbiosis. PHB granules occurred in undergoing senescence bacteroids, which indicated that the energy and carbon metabolism has shifted (Xie et al., 2011). The PHB and tricarboxylic acid (TCA) cycles both start with acetylCoA. Under aerobic conditions, the TCA cycle is responsible for the complete oxidation of acetyl-CoA and formation of intermediates required for ATP production, but under oxygen limitation condition, when there is an inhibition of the TCA cycle by NADH or NADPH, the bacteroids favor PHB synthesis. During PHB synthesis, there is apparently a concomitant reduction in protein synthesis, a process coupled to ATP formation and utilization ( $\mathrm{Tal}$ et al., 1990). In the symbiosis of the GmcA-deficiency mutant RLgmcA, the low expression of the catalase-peroxidase gene (katG), alpha/beta hydrolase (pRL80022), carbon monoxide dehydrogenase (pRL80023), succinate-semialdehyde dehydrogenase (pRL120603), and alcohol dehydrogenase (pRL90027) inhibited NAD(P)H oxidase activity. To allow continued operation of the TCA cycle, $\mathrm{NAD}(\mathrm{P}) \mathrm{H}$ was channeled into other biosynthesis reactions, such as $\mathrm{PHB}$ synthesis, for acting as reducing equivalents (Xie et al., 2011).

The $g m c A$ gene expression is significantly up-regulated during the whole nodulation process, and its highest expression level occurred at 42 days after inoculation. Moreover, the

\section{REFERENCES}

Ahmad, B., Haq, S. K., Varshney, A., Moosavi-Movahedi, A. A., and Khan, R. H. (2010). Effect of trifluoroethanol on native and acid-induced states of glucose oxidase from Aspergillus niger. Biochemistry 75, 486-493. doi: 10.1134/ S0006297910040139
R. leguminosarum gmcA mutant was unable to compete efficiently in the rhizosphere with its wild-type parent, which shows that bacterial GmcA is important for adaptation to the microenvironment of the plant host. Overall, considering the poor nitrogen-fixing ability of its nodules, the mutant in $g m c A$ gene had a profound influence on the whole nodulation process.

\section{DATA AVAILABILITY STATEMENT}

The mass spectrometry proteomics data have been deposited to the ProteomeXchange Consortium via the PRIDE partner repository with the dataset identifier PXD017485.

\section{AUTHOR CONTRIBUTIONS}

GC conceived and designed the study. QZ, SL, and HW performed the experiments. GC, QZ, DH, and XL analyzed the results. GC and QZ wrote the manuscript. All authors read and approved the final manuscript.

\section{FUNDING}

This study was supported by the National Natural Science Foundation of China (grant no. 31772399) and the Fundamental Research Funds for the Central Universities, South-Central University for Nationalities (grant no. CZY18022).

\section{ACKNOWLEDGMENTS}

The authors thank PTM Biolabs Co., Ltd. (Hangzhou, China) for the mass spectrometry analysis.

\section{SUPPLEMENTARY MATERIAL}

The Supplementary Material for this article can be found online at: https://www.frontiersin.org/articles/10.3389/fmicb. 2020.00394/full\#supplementary-material

FIGURE S1 | Analysis of the protein domains of GmcA in Rhizobium leguminosarum 3841. BetA, choline dehydrogenase or related flavoprotein; GMC_oxred_C, GMC oxidoreductase; GMC_mycofac_2, GMC family mycofactocin-associated oxidoreductase.

FIGURE S2 | Plant growth test of the symbiotic ability of $R$. leguminosarum. (A) Control plant root inoculated with the wild type RL3841, (B) Plant root inoculated with RLgmcA. 
Appl. Environ. Microbiol. 68, 4915-4924. doi: 10.1128/AEM.68.10.4915-4924. 2002

Barr, M., East, A. K., Leonard, M., Mauchline, T. H., and Poole, P. S. (2008). in vivo expression technology (IVET) selection of genes of Rhizobium leguminosarum biovar viciae A34 expressed in the rhizosphere. FEMS Microbiol. Lett. 282, 219-227. doi: 10.1111/j.1574-6968.2008.01131.x

Beckett, R. P., Ntombela, N., Scott, E., Gurjanov, O. P., Minibayeva, F. V., and Liers, C. (2015). LiersRole of laccases and peroxidases in saprotrophic activities in the lichen Usnea undulata. Fungal Ecol. 14, 71-78. doi: 10.1016/j.funeco.2014.12. 004

Beringer, J. E., and Hopwood, D. A. (1976). Chromosomal recombination and mapping in Rhizobium leguminosarum. Nature 264, 291-293. doi: 10.1038/ $264291 \mathrm{a} 0$

Bhat, S. V., Booth, S. C., McGrath, S. G. K., and Dahms, T. E. S. (2015). Rhizobium leguminosarum bv. viciae 3841 Adapts to 2,4-dichlorophenoxyacetic acid with "Auxin-Like" morphological changes, cell envelope remodeling and upregulation of central metabolic pathways. PLOS ONE 10:e123813. doi: 10. 1371/journal.pone.0123813

Bisogno, F., Rioz-Martínez, A., Rodríguez, C., Lavandera, I., De Gonzalo, G., Torres Pazmino, D., et al. (2010). Oxidoreductases working together: concurrent obtaining of valuable derivatives by employing the PIKAT method. Chemcatchem 2, 946-949. doi: 10.1002/cctc.201000115

Blanco, F. A., Meschini, E. P., Zanetti, M. E., and Aguilar, O. M. (2009). A small gtpase of the rab family is required for root hair formation and preinfection stages of the common bean-rhizobium symbiotic association. Plant Cell 21, 2797-2810. doi: $10.2307 / 40537042$

Capela, D., Filipe, C., Bobik, C., Batut, J., and Bruand, C. (2006). Sinorhizobium meliloti differentiation during symbiosis with alfalfa: a transcriptomic dissection. Mol. Plant Microbe Interact. 19, 363-372. doi: 10.1094/MPMI-190363

Cavener, D. R. (1992). Gmc oxidoreductases. A newly defined family of homologous proteins with diverse catalytic activities. J. Mol. Biol. 223, 811-814. doi: 10.1016/0022-2836(92)90992-S

Chao, T. C., Buhrmester, J., Hansmeier, N., Puhler, A., and Weidner, S. (2005). Role of the regulatory gene rirA in the transcriptional response of Sinorhizobium meliloti to iron limitation. Appl. Environ. Microb. 71, 5969-5982. doi: 10.1128/ AEM.71.10.5969-5982.2005

Cheng, G., Karunakaran, R., East, A. K., Munozazcarate, O., and Poole, P. S. (2017). Glutathione affects the transport activity of Rhizobium leguminosarum 3841 and is essential for efficient nodulation. FEMS Microbiol. Lett. 364:fnx045. doi: $10.1093 /$ femsle/fnx045

Clarke, T. A., Fairhurst, S., Lowe, D. J., Watmough, N. J., and Eady, R. R. (2011). Electron transfer and half-reactivity in nitrogenase. Biochem. Soc. Trans. 39:201. doi: 10.1042/BST0390201

Cox, J., and Mann, M. (2008). MaxQuant enables high peptide identification rates, individualized p.p.b.-range mass accuracies and proteome-wide protein quantification. Nat. Biotechnol. 26, 1367-1372. doi: 10.1038/nbt.1511

Etxebeste, O., Herrero-García, E., Cortese, M. S., Garzia, A., Oiartzabal-Arano, E., de los Ríos, V., et al. (2012). GmcA is a putative glucose-methanol-choline oxidoreductase required for the induction of asexualdevelopment in Aspergillus nidulans. PLoS ONE 7:e40292. doi: 10.1371/journal.pone.0040292

Ferreira, P., Carro, J., Serrano, A., and Martínez, A. T. (2015). A survey of genes encoding $\mathrm{H} 2 \mathrm{O} 2$-producing gmc oxidoreductases in 10 polyporales genomes. Mycologia 107, 1105-1119. doi: 10.3852/15-027

Figurski, D. H., and Helinski, D. R. (1979). Replication of an origin-containing derivative of plasmid RK2 dependent on a plasmid function provided in trans. Proc. Natl. Acad. Sci. U.S.A. 76, 1648-1652. doi: 10.1073/pnas.76.4.1648

Giergiel, M., Lopucki, M., Stachowicz, N., and Kankofer, M. (2012). The influence of age and gender on antioxidant enzyme activities in humans and laboratory animals. Aging Clin. Exp. Res. 24, 561-569. doi: 10.3275/8587

Goss, T., Twachtmann, M., Mulkidjanian, A., Steinhoff, H. J., Klare, J. P., Hanke, G. T., et al. (2012). Impact of ferredoxin:nadp(h) oxidoreductase on redox poise of the glutathione pool and fenton reaction capacity of thylakoid membranes: a connection to pre-acquired acclimation in arabidopsis. Free Radical Biol. Med. 53:S42. doi: 10.1016/j.freeradbiomed.2012.08.509

$\mathrm{Gu}$, S. Y., Yan, X. X., and Liang, D. C. (2008). Crystal structure of tflp: a ferredoxinlike metallo- $\beta$-lactamase superfamily protein from Thermoanaerobacter tengcongensis. Proteins 72, 531-536. doi: 10.1002/prot.22069
Haney, C. H., and Long, S. R. (2010). Plant flotillins are required for infection by nitrogen-fixing bacteria. Proc. Natl. Acad. Sci. U.S.A. 107, 478-483. doi: $10.2307 / 40536299$

Hollmann, F., and Schmid, A. (2004). Electrochemical regeneration of oxidoreductases for cell-free biocatalytic redox reactions. Biocatalysis 22, 63-88. doi: 10.1080/10242420410001 692778

Iida, K., Cox-Foster, D. L., Yang, X., Ko, W. Y., and Cavener, D. R. (2007). Expansion and evolution of insect gmc oxidoreductases. BMC Evol. Biol. 7:75. doi: 10.1186/1471-2148-7-75

Islam, T., Manna, M., and Reddy, M. K. (2015). Glutathione peroxidase of Pennisetum glaucum (PgGPx)is a functional $\mathrm{Cd} 2+$ dependent peroxiredoxin that enhances tolerance against salinity and drought stress. PLoS ONE 10:e0143344. doi: 10.1371/journal.pone.0143344

Janczarek, M., Rachwał, K., Marzec, A., Grządziel, J., and Palusińska-Szysz, M. (2015). Signal molecules and cell-surface components involved in early stages of the legume-rhizobium interactions. Appl. Soil Ecol. 85, 94-113. doi: 10.1016/ j.apsoil.2014.08.010

Jeelani, G., Husain, A., Sato, D., Ali, V., Suematsu, M., Soga, T., et al. (2010). Two atypical L-cysteine-regulated nadph-dependent oxidoreductases involved in redox maintenance, L-cystine and iron reduction, and metronidazole activation in the enteric protozoan Entamoeba histolytica. J. Biol. Chem. 285, 26889-26899. doi: $10.1074 /$ jbc.M110.106310

Johnston, A. W., and Beringer, J. E. (1975). Identification of the rhizobium strains in pea root nodules using genetic markers. J. Gen. Microbiol. 87, 343-350. doi: 10.1099/00221287-87-2-343

Jung, I. L., and Kim, I. G. (2003). Transcription of $a h p C$, $k a t G$, and katE genes in Escherichia coli is regulated by polyamines: polyamine-deficient mutant sensitive to H2O2-induced oxidative damage. Biochem. Bioph. Res. Co. 301, 915-922. doi: 10.1016/s0006-291x(03)00064-0

Karunakaran, R., Eber, T. K., Harvey, S., Leonard, M. E., Ramachandran, V., and Poole, P. S. (2006). Thiamine is synthesized by a salvage pathway in Rhizobium leguminosarum bv. viciae strain 3841. J. Bacteriol. 188, 6661-6668. doi: 10.1128/ jb.00641-06

Karunakaran, R., Haag, A. F., East, A. K., Ramachandran, V. K., Prell, J., James, E. K., et al. (2010). BacA is essential for bacteroid development in nodules of galegoid, but not phaseoloid, legumes. J. Bacteriol. 192, 2920-2928. doi: 10.1128/JB.00020-10

Karunakaran, R., Ramachandran, V. K., Seaman, J. C., East, A. K., Mouhsine, B., Mauchline, T. H., et al. (2009). Transcriptomic analysis of Rhizobium leguminosarum bv. viciae in symbiosis with host plants Pisum sativum and Vicia cracca. J. Bacteriol. 191, 4002-4014. doi: 10.1128/JB.00165-09

Liu, X., Ohta, T., Kawabata, T., and Kawai, F. (2013). Catalytic mechanism of short ethoxy chain nonylphenol dehydrogenase belonging to a polyethylene glycol dehydrogenase group in the gmc oxidoreductase family. Int. J. Mol. Sci. 14, 1218-1231. doi: 10.3390/ijms14011218

López-Baena, F. J., Ruiz-Sainz, J. E., Rodríguez-Carvajal, M. A., and Vinardell, J. M. (2016). Bacterial molecular signals in the Sinorhizobium fredii-soybean symbiosis. Int. J. Mol. Sci. 17:755. doi: 10.3390/ijms17050755

Okazaki, S., Tittabutr, P., Teulet, A., Thouin, J., and Giraud, E. (2015). Rhizobiumlegume symbiosis in the absence of nod factors: two possible scenarios with or without the T3SS. ISME J. 10, 193-203. doi: 10.1038/ismej.2015.103

Pfaffl, M. W., Horgan, G. W., and Dempfle, L. (2002). Relative expression software tool $(\operatorname{REST}(\mathrm{c}))$ for group-wise comparison and statistical analysis of relative expression results in real-time PCR. Nucleic Acids Res. 30:E36. doi: 10.1093/ nar/30.9.e36

Poole, P. S., Blyth, A., Reid, C., and Walters, K. (1994). myo-Inositol catabolism and catabolite regulation in Rhizobium leguminosarum bv. viciae. Microbiology 140, 2787-2795. doi: 10.1099/00221287-140-10-2787

Prell, J., Bourdès, A., Karunakaran, R., Lopez-Gomez, M., and Poole, P. S. (2009). Pathway of \{gamma\}-aminobutyrate (GABA) metabolism in Rhizobium leguminosarum 3841 and its role in symbiosis. J. Bacteriol. 191, 2177-2186. doi: 10.1128/JB.01714-08

Rahfeld, P., Kirsch, R., Kugel, S., Wielsch, N., Stock, M., Groth, M., et al. (2014). Independently recruited oxidases from the glucose-methanol-choline oxidoreductase family enabled chemical defences in leaf beetle larvae (subtribe Chrysomelina) to evolve. Proc. R. Soc. B 281, 20140842. doi: 10.1098/rspb.2014. 0842 
Rohr, C. O., Levin, L. N., Mentaberry, A. N., Wirth, S. A., and Monika, S. (2013). A first insight into Pycnoporus sanguineus BAFC 2126 transcriptome. PLoS ONE 8:e81033. doi: 10.1371/journal.pone.0081033

Seefeldt, L. C., Yang, Z. Y., Duval, S., and Dean, D. R. (2013). Nitrogenase reduction of carbon-containing compounds. Biochim. Biophys. Acta 1827, 1102-1111. doi: 10.1016/j.bbabio.2013.04.003

Smith, P. K., Krohn, R. I., and Hermanson, G. T. (1985). Measurement of protein using bicinchoninic acid. Anal. Biochem. 163, 76-85. doi: 10.1016/00032697(85)90442-7

Sützl, L., Laurent, C. V. F. P., Abrera, A. T., Schütz, G., Ludwig, R., and Haltrich, D. (2018). Multiplicity of enzymatic functions in the CAZy AA3 family. Appl. Microbiol. Biotechnol. 102, 2477-2492. doi: 10.1007/s00253-018-8784-0

Takanashi, K., Yokosho, K., Saeki, K., Sugiyama, A., Sato, S., Tabata, S., et al. (2013). LjMATE1: a citrate transporter responsible for iron supply to the nodule infection zone of Lotus japonicus. Plant Cell Physiol. 54, 585-594. doi: 10.1093/ pcp/pct118

Tal, S., Smirnoff, P., and Okon, Y. (1990). Purification and characterization of D(2)-b-hydroxybutyrate dehydrogenase from Azospirillum brasilense Cd. J. Gen. Microbiol. 136, 645-649. doi: 10.1099/00221287-136-4-645

Vargas Mdel, C., Encarnacion, S., Davalos, A., Reyes-Perez, A., Mora, Y., Garcia-de los Santos, A., et al. (2003). Only one catalase, katG, is detectable in Rhizobium etli, and is encoded along with the regulator OxyR on a plasmid replicon. Microbiology 149, 1165-1176. doi: 10.1099/mic.0. 25909-0

Vincill, E. D., Szczyglowski, K., and Roberts, D. M. (2005). GmN70 and LjN70. Anion transporters of the symbiosome membrane of nodules with a transport preference for nitrate. Plant Physiol. 137, 1435-1444. doi: 10.1104/pp.104. 051953

Xie, F., Cheng, G., Xu, H., Wang, Z., Lei, L., and Li, Y. (2011). Identification of a novel gene for biosynthesis of a bacteroid-specific electron carrier menaquinone. PLoS ONE 6:e28995. doi: 10.1371/journal.pone.0028995

Yan, H., Xiao, G., Zhang, J., Hu, Y., Yuan, F., Cole, D. K., et al. (2004). SARS coronavirus induces apoptosis in Vero E6 cells. J. Med. Virol. 73, 323-331. doi: 10.1002/jmv.20094

Yilmaz, J. L., and Bülow, L. (2010). Enhanced stress tolerance in Escherichia coli and Nicotiana tabacum expressing a betaine aldehyde dehydrogenase/choline dehydrogenase fusion protein. Biotechnol. Progr. 18, 1176-1182. doi: 10.1021/ bp020057k

Young, J. P., Crossman, L., Johnston, A., Thomson, N., Ghazoui, Z., Hull, K., et al. (2006). The genome of Rhizobium leguminosarum has recognizable core and accessory components. Genome Biol. 7:R34.

Conflict of Interest: The authors declare that the research was conducted in the absence of any commercial or financial relationships that could be construed as a potential conflict of interest.

Copyright (c) $2020 \mathrm{Zou}, \mathrm{Luo}, \mathrm{Wu}, \mathrm{He}, \mathrm{Li}$ and Cheng. This is an open-access article distributed under the terms of the Creative Commons Attribution License (CC BY). The use, distribution or reproduction in other forums is permitted, provided the original author(s) and the copyright owner(s) are credited and that the original publication in this journal is cited, in accordance with accepted academic practice. No use, distribution or reproduction is permitted which does not comply with these terms. 